\title{
Effect of propranolol on left ventricular function, segmental wall motion, and diastolic pressure-volume relation in $\operatorname{man}^{1,2}$
}

\author{
D. John Coltart, ${ }^{3}$ Edwin L. Alderman, Sherilyn C. Robison, and Donald C. Harrison \\ From the Cardiology Division, Stanford University Medical Center, Stanford, California, U.S.A.
}

Precise quantitation of the effects of the non-selective beta adrenergic blocking drug propranolol (o.15 mg/kg body weight) on left ventricular function, segmental wall motion, and diastolic pressure-volume relation in man has been performed. High fidelity left ventricular pressure measurements and simultaneous single-plane angiocardiograms were recorded on a video disc and volumes calculated by a light-pen computer system. Systolic segmental wall motion was computer analysed using the long axis-quadrasection method. Patients were transvenously atrially paced to maintain a constant heart rate.

The haemodynamic effects of propranolol may vary depending upon the extent of pre-existing myocardial disease. In some patients ventricular function, as measured by ejection fraction, may be reduced. This reduction in ejection fraction appears to result from overall reduction in segmental wall motion, but also from accentuation of segmental wall abnormalities. These results are consistent with the thesis that beta adrenergic blocking drugs may inhibit compensatory sympathetic mechanisms.

The diastolic effects of propranolol may include quite substantial increases in ventricular volumes in those patients with impaired cardiac function. With respect to the intact human ventricle, propranolol may increase diastolic volume for a given level of ventricular pressure. Thus, in a static sense, the ventricle in these patients could be viewed as being more compliant after propranolol administration. However, the fact that the lengthtension relation, as measured by the slope of the logarithmic pressure versus volume plot is unaltered by propranolol, suggests that the muscle comprising the ventricle itself exhibits no alteration in its passive elastic properties.

The non-selective beta-adrenergic blocking drug propranolol is widely used in clinical practice for the treatment of patients with ischaemic heart disease, hypertension, arrhythmias, and obstructive cardiomyopathy.

Many haemodynamic studies have been reported in the past documenting the effects of propranolol on ventricular function. Because propranolol has a strong negative chronotropic effect, it has not always been possible in these studies to isolate the direct

\footnotetext{
Received 30 October 1974.

${ }^{1}$ Presented in part to the American Heart Association, Atlantic City, New Jersey, November 1973; and the British Cardiac Society, London, December 1973.

${ }^{2}$ This work was supported in part by N.I.H. Grants. Dr. Coltart was supported by the Peel Medical Research Trust of Great Britain and the Lilly International Fellowship Programme, and Imperial Chemical Industries, Ltd.

${ }^{3}$ Present address: St. Thomas' Hospital, London SEr $7 \mathrm{EH}$.
}

effects of propranolol from the secondary effects of heart rate slowing. The purpose of this study is to examine the influence of propranolol on ventricular function, segmental wall motion, and diastolic pressure-volume relation in patients with controlled heart rates.

\section{Patient selection}

Patients were selected from those scheduled for cardiac catheterization as part of a routine diagnostic study of suspected coronary artery disease. The full catheterization procedure was explained and informed consent willingly given in all cases. Coronary angiograms were performed on a subsequent day. No mitral or aortic regurgitation was observed in any patient. The results obtained in 8 patients are presented; patients in whom the stroke volume determined by dye dilution differed from the stroke volume by the angiocardiographic volume method by more than ro per cent were 
excluded. This excluded patients with septal asynergy which might cause error in single plane area-length volume calculation.

\section{Haemodynamic measurements}

Cardiac catheterization was performed with the patients in a fasting state, after $100 \mathrm{mg}$ oral quinalbarbitone as premedication. A Cournand catheter was inserted into the pulmonary artery via a median antecubital vein and a No. 6 bipolar pacing catheter was inserted via a sheath in the left femoral vein, with the tip positioned against the right atrial wall. A micro-tip pressure transducer (Millar Instruments, Inc., Houston, Texas) was inserted by brachial arteriotomy and positioned in the left ventricle. The catheter contains side-holes enabling simultaneous injection of contrast for left ventricular visualization. Cardiac output determinations were made from dye curves obtained by injecting Indocyanine green dye into the pulmonary artery and sampling from the left ventricle.

After placement of the catheters, atrial pacing was started at the lowest possible rate at which stable capture and pacing was obtained; this was generally 5 to 6 beats/ minute above the basal rate. After 5 minutes of pacing, duplicate indicator dye dilution cardiac output estimations were made. The patient was then placed in the $30^{\circ}$ right anterior oblique projection and carefully instructed in breath-holding. Care was taken to ensure complete atrial capture at all times. Simultaneous left ventriculogram and pressure measurements were then obtained with $50 \mathrm{ml}$ Renografin 76 through the Millar catheter. The ventriculogram and simultaneous pressure were recorded and stored at 30 frames/second on a video disc and subsequently displayed on a video monitor. This video system, as previously described (Alderman et al., 1973) has been designed to give accurate and reproducible volume measurements from single plane cine angiocardiograms by the area-length method. Simultaneous recording of electrocardiograms and left ventricular pressure as individual horizontal bars on each video frame was incorporated in this study. Any angiocardiograms containing premature beats were omitted from the analysis.

Following the control angiocardiogram the patient was returned to the horizontal position and propranolol $0.15 \mathrm{mg} / \mathrm{kg}$ body weight was infused over 5 minutes through the pulmonary artery catheter. Pacing was continued throughout the whole procedure. Twenty minutes from the end of the infusion of propranolol the dye dilution cardiac outputs were repeated. After this the patient was returned to the identical right anterior oblique projection and the simultaneous pressure and volume measurements again repeated.

Using light-pen computer processing of the video image for determination of the left ventricular volume, simultaneous frame-by-frame analysis of pressure volume data was performed.

Analysis of systolic left ventricular wall motion was made by means of a computer using the long-axisquadrasection method. The left ventricular margins were defined manually by the light-pen system and the
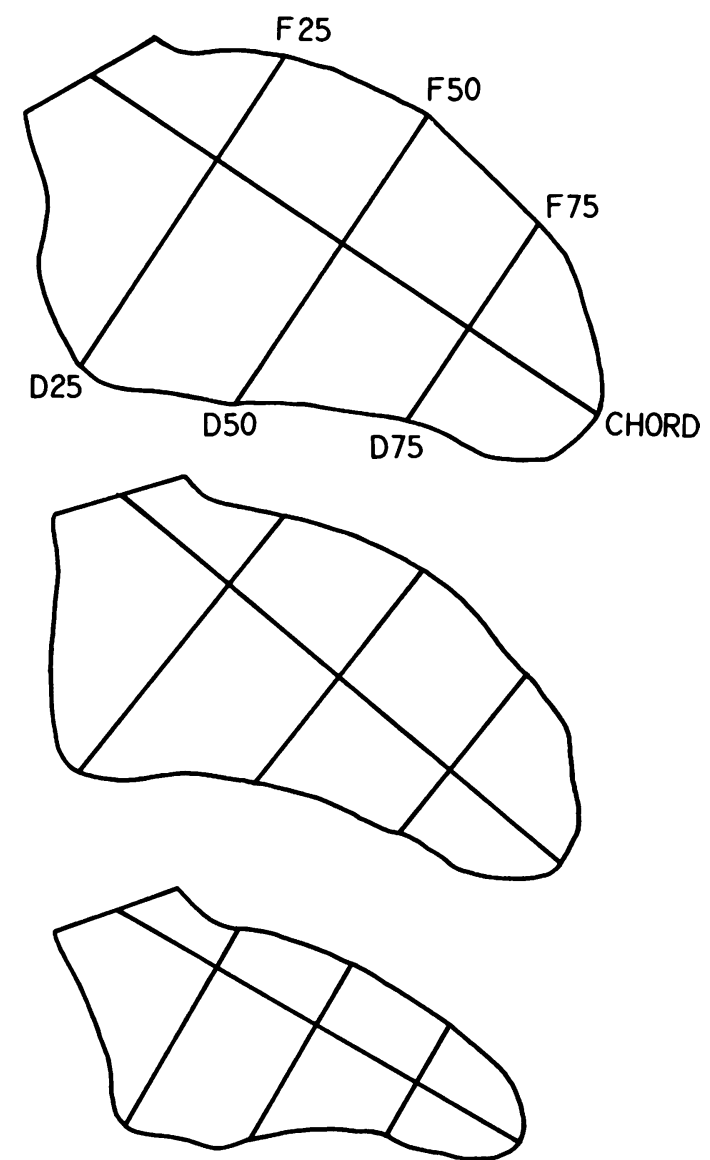

FIG. I See text.

data were entered into the computer which divides the distance from aortic valve to apex into four equal portions by three perpendicular transverse diameters which are further divided into six perpendicular radii (Fig. I). The radii are designated at the 25,50 , and 75 per cent distance along both the free wall (F) and diaphragmatic wall (D) of the left ventricle. The percentage length change from diastole to systole was calculated for each of these perpendicular radii and long axis chord and averaged for each patient.

\section{Theory of pressure-volume measurements}

Gaasch et al. (1972) have noted that the diastolic pressure $(P)$ volume $(V)$ relation of the left ventricle may be represented by a straight line on a plot of natural $\operatorname{logarithm}(\log ) \mathrm{P}$ against $\mathrm{V}$, with a slope $k$ and a $\log P$ intercept $b$. A minimum of two $P$ and $V$ data points is necessary to define these constants and it was the purpose of this study to generate as many data points during diastole as possible by prolonging controlled diastole. For the intact ventricle $\mathrm{dP} / \mathrm{dV}=\mathrm{kP}+\mathrm{C}$, where $\mathrm{dP} / \mathrm{dV}$ is ventricular stiffness, $\mathrm{k}$ the stiffness coefficient, 
and $\mathrm{C}$ the $\mathrm{dP} / \mathrm{dV}$ at zero pressure. $\mathrm{C}$ is small and has been assumed to be negligible at physiological filling pressures and volumes. Thus $\mathrm{dP} / \mathrm{dV}=\mathrm{kP}$; rearranging gives $d P / P=k d V$ and integrated produces $\log P=k V+b$ as a constant of integration. In this study, pressurevolume data are presented as pressure-volume curves (e.g. Fig. 10) and as log pressure-volume curves (e.g. Fig. II). Regression equations (Table 2) are derived from the linear portion of pressure-volume curves.

\section{Results}

\section{Ventricular function}

Fig. 2 shows the changes in ejection fraction and end-diastolic volumes which resulted from propranolol administration. Four patients showed only small change in either ejection fraction or enddiastolic volume while 4 other patients had declines

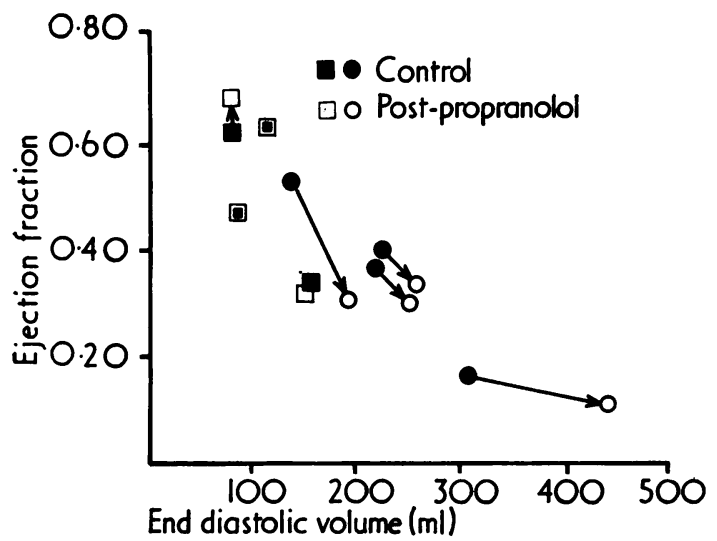

FIG. 2 Comparison of ejection fraction and enddiastolic volume before and after propranolol administration. Control observations are shown in closed squares and circles, and after the drug in the open squares and circles. Group $A$ patients are shown in squares and group $B$ patients in circles. in ejection fraction ranging from 0.05 to 0.22 and increases in end-diastolic volume ranging from 30 to $135 \mathrm{ml}$. There were no significant changes either in left ventricular end-diastolic pressure (Fig. 3) or aortic systolic pressure (Fig. 4) between control and propranolol angiograms which might account for this change. The 4 patients showing no significant reduction in cardiac function after propranolol will be referred to as group $A$ and the 4 patients showing depressed cardiac performance after propranolol will be referred to as group B.

Table I shows that the group B patients who had shown diminished ejection fraction and increased diastolic volume after propranolol administration had lower initial ejection fractions and higher initial end-diastolic volumes than did group $\mathbf{A}$ patients. Two of the group A patients did not have coronary disease and had normal left ventriculograms, whereas all 4 of the group B patients had advanced

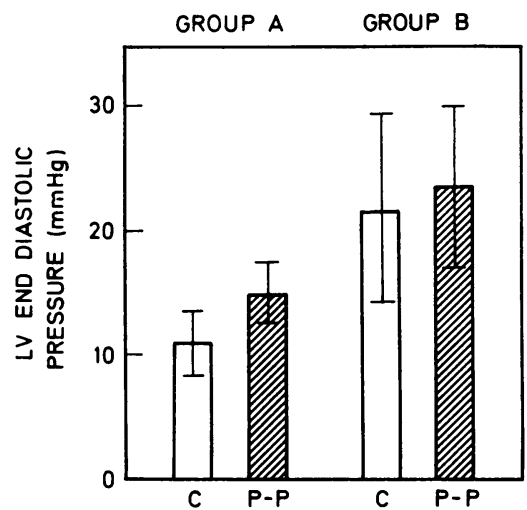

FIG. 3 The effect of propranolol on left ventricular end-diastolic pressure in group $A$ and group $B$ patients. Control observations $(C)$ are shown in the open histograms and observations after propranolol $(P-P)$ with the crossed histograms.

TABLE I Clinical data (mean $\pm S E M)$

\begin{tabular}{|c|c|c|c|c|}
\hline Response to propranolol & & Group $A(N=4)$ & Group $B(N=4)$ & $A$ versus $B$ \\
\hline Ejection fraction & $\begin{array}{l}\text { Pre } \\
\text { Post }\end{array}$ & $\begin{array}{r}0.52 \pm 0.07 \\
0.53 \pm 0.08 \\
N S\end{array}$ & $\begin{array}{l}0.36 \pm 0.07 \\
0.27 \pm 0.05 \\
\text { NS }\end{array}$ & $\begin{array}{l}\text { NS } \\
\text { NS }\end{array}$ \\
\hline End-diastolic volume (ml) & $\begin{array}{l}\text { Pre } \\
\text { Post }\end{array}$ & $\begin{array}{l}105.2 \pm 17.3 \\
105.5 \pm 16.3 \\
\text { NS }\end{array}$ & $\begin{array}{l}221.0 \pm 34.5 \\
284.0 \pm 53.9 \\
N S\end{array}$ & $\begin{array}{l}P<0.05 \\
P<0.05\end{array}$ \\
\hline Coronary angiography & & $\begin{array}{l}2 \text { - normal } \\
2 \text { - two vessel disease }\end{array}$ & $\begin{array}{l}2 \text { - two vessel disease } \\
2 \text { - three vessel disease }\end{array}$ & \\
\hline LV angiogram & & $\begin{array}{l}2 \text { - normal } \\
2 \text { - mild hypokinesis }\end{array}$ & 4 - akinetic areas & \\
\hline
\end{tabular}




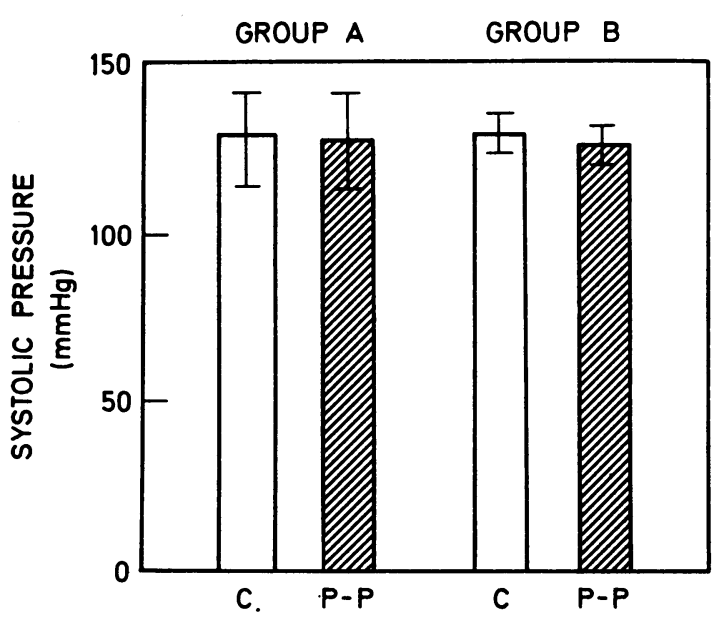

FIG. 4 The effect of propranolol on systolic pressure in patients in group $A$ and group $B$. Conventions as in Fig. 3.

coronary disease with previous myocardial infarctions.

\section{Segmental wall motion (Fig. 5)}

The number of individuals studied was small, so though the control average percentage shortening was less in the group B patients than in the group A

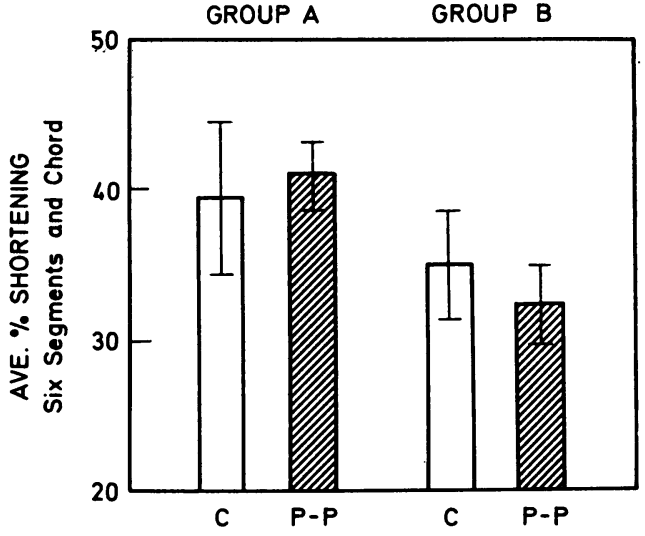

FIG. 5 The effect of propranolol on the average percentage shortening of the axis segmental radii and chord in group $A$ and group $B$ patients. Conventions as in Fig. 3.

patients, it was not significantly so $(35.25 \pm 3.5$ versus $39.5 \pm 5.0, P=0.6$ ). Propranolol administration caused no significant change in wall motion in either group of patients $(35.25 \pm 3.5$ to $32.5 \pm 2.5$, $P=0.09$, in group $B ; 39.5 \pm 5.0$ to $41.25 \pm 2.2$, $\mathbf{P}=0.6$, in group $A)$. There were two individual patients in group B who after propranolol developed abnormalities of wall motion in previously

TABLE 2 Haemodynamic response to propranolol

\begin{tabular}{|c|c|c|c|c|c|c|c|c|c|}
\hline $\begin{array}{l}\text { Group } \\
\text { Case no. } \\
\text { Coronary anatomy }\end{array}$ & & $\begin{array}{l}\text { A } \\
I \\
\text { Normal }\end{array}$ & $\begin{array}{l}A \\
2 \\
2 \text { vessels }\end{array}$ & $\begin{array}{l}A \\
3 \\
2 \text { vessels }\end{array}$ & $\begin{array}{l}A \\
4 \\
\text { Normal }\end{array}$ & $\begin{array}{l}B \\
I \\
3 \text { vessels }\end{array}$ & $\begin{array}{l}B \\
2 \\
2 \text { vessels }\end{array}$ & $\begin{array}{l}B \\
3 \\
2 \text { vessels }\end{array}$ & $\begin{array}{l}B \\
4 \\
3 \text { vessels }\end{array}$ \\
\hline Ejection fraction & $\begin{array}{l}\text { Pre } \\
\text { Post }\end{array}$ & $\begin{array}{l}62 \\
68\end{array}$ & $\begin{array}{l}47 \\
49\end{array}$ & $\begin{array}{l}34 \\
32\end{array}$ & $\begin{array}{l}63 \\
63\end{array}$ & $\begin{array}{l}40 \\
34\end{array}$ & $\begin{array}{l}53 \\
31\end{array}$ & $\begin{array}{l}37 \\
31\end{array}$ & $\begin{array}{l}17 \\
12\end{array}$ \\
\hline Systolic pressure $(\mathrm{mmHg})$ & $\begin{array}{l}\text { Pre } \\
\text { Post }\end{array}$ & $\begin{array}{l}170 \\
170\end{array}$ & $\begin{array}{l}110 \\
106\end{array}$ & $\begin{array}{l}124 \\
130\end{array}$ & $\begin{array}{l}108 \\
103\end{array}$ & $\begin{array}{l}135 \\
135\end{array}$ & $\begin{array}{l}135 \\
135\end{array}$ & $\begin{array}{l}130 \\
129\end{array}$ & $\begin{array}{l}\text { II } 4 \\
\text { IIO }\end{array}$ \\
\hline LVEDP (mmHg) & $\begin{array}{l}\text { Pre } \\
\text { Post }\end{array}$ & $\begin{array}{l}4 \\
8\end{array}$ & $\begin{array}{l}15 \\
16\end{array}$ & $\begin{array}{l}15 \\
19\end{array}$ & $\begin{array}{l}10 \\
17\end{array}$ & $\begin{array}{l}13 \\
13\end{array}$ & $\begin{array}{l}16 \\
18\end{array}$ & $\begin{array}{l}42 \\
42\end{array}$ & $\begin{array}{l}15 \\
21\end{array}$ \\
\hline Cardiac output (1/min) & $\begin{array}{l}\text { Pre } \\
\text { Post }\end{array}$ & $\begin{array}{l}3.9 \\
4.4\end{array}$ & $\begin{array}{l}3.6 \\
4.7\end{array}$ & $\begin{array}{l}4.2 \\
3.9\end{array}$ & $\begin{array}{l}3.6 \\
3.2\end{array}$ & $\begin{array}{l}6.4 \\
6.4\end{array}$ & $\begin{array}{l}5.4 \\
4.8\end{array}$ & $\begin{array}{l}5.2 \\
4.8\end{array}$ & $\begin{array}{l}4.4 \\
4.4\end{array}$ \\
\hline $\begin{array}{l}\mathrm{LV}(\mathrm{dp} / \mathrm{dt}) \\
\quad\left(\mathrm{mmHg} \mathrm{s}^{-1}\right)\end{array}$ & $\begin{array}{l}\text { Pre } \\
\text { Post }\end{array}$ & $\begin{array}{l}1450 \\
1450\end{array}$ & $\begin{array}{l}1500 \\
1150\end{array}$ & $\begin{array}{l}1300 \\
1250\end{array}$ & $\begin{array}{l}1500 \\
1450\end{array}$ & $\begin{array}{l}2200 \\
2050\end{array}$ & $\begin{array}{l}1290 \\
1050\end{array}$ & $\begin{array}{l}1000 \\
1000\end{array}$ & $\begin{array}{r}1000 \\
950\end{array}$ \\
\hline $\begin{array}{l}\text { End-diastolic volume } \\
\quad(\mathrm{ml})\end{array}$ & $\begin{array}{l}\text { Pre } \\
\text { Post }\end{array}$ & $\begin{array}{l}80 \\
82\end{array}$ & $\begin{array}{l}80 \\
80\end{array}$ & $\begin{array}{l}152 \\
150\end{array}$ & $\begin{array}{l}109 \\
110\end{array}$ & $\begin{array}{l}225 \\
256\end{array}$ & $\begin{array}{l}136 \\
192\end{array}$ & $\begin{array}{l}218 \\
248\end{array}$ & $\begin{array}{l}305 \\
440\end{array}$ \\
\hline \multicolumn{10}{|c|}{ Linear regression of pressure-volume plot } \\
\hline Pre & $\begin{array}{l}\mathbf{r} \\
\mathbf{a} \\
\mathbf{b}\end{array}$ & $\begin{array}{l}0.90 \\
0.11 \\
-5.5\end{array}$ & $\begin{array}{r}0.99 \\
0.89 \\
-45.7\end{array}$ & $\begin{array}{r}0.92 \\
0.12 \\
-1.4\end{array}$ & $\begin{array}{r}0.96 \\
0.30 \\
-22.8\end{array}$ & $\begin{array}{r}0.96 \\
0.14 \\
-17.6\end{array}$ & $\begin{array}{r}0.96 \\
0.24 \\
-18.5\end{array}$ & $\begin{array}{r}0.89 \\
0.35 \\
-36.2\end{array}$ & $\begin{array}{r}0.81 \\
0.09 \\
-15.6\end{array}$ \\
\hline Post & $\begin{array}{l}\mathbf{r} \\
\mathbf{a} \\
\mathrm{b} \\
\mathrm{N}=\end{array}$ & $\begin{array}{c}0.94 \\
0.22 \\
-\mathrm{I} 1.4 \\
5\end{array}$ & $\begin{array}{r}0.76 \\
0.92 \\
-57.6 \\
4\end{array}$ & $\begin{array}{c}0.98 \\
0.06 \\
11.5 \\
4\end{array}$ & $\begin{array}{r}0.97 \\
0.38 \\
-24.2 \\
18\end{array}$ & $\begin{array}{r}0.85 \\
0.17 \\
-31.4 \\
6\end{array}$ & $\begin{array}{c}0.95 \\
0.12 \\
-5.9 \\
5\end{array}$ & $\begin{array}{c}0.96 \\
0.46 \\
-69.3 \\
8\end{array}$ & $\begin{array}{r}0.85 \\
0.23 \\
-81.6 \\
7\end{array}$ \\
\hline
\end{tabular}

For conversion from traditional units to SI units: $\mathrm{I} \mathrm{mm} \mathrm{Hg} \approx 0.133 \mathrm{kPa}$. 
hypokinetic areas. For example, Fig 6-8 show the segmental wall motion in one patient from group B for all 6 radii, long chord, and volume plots. An increase was observed in end-diastolic lengths (in all segments) reflecting the larger ventricular size found in this group of patients and hence resulting in a decreased overall percentage segmental length shortening. The apex in the pre-propranolol study (D 75 and F 75) was relatively hypokinetic. After propranolol five of the six segments showed increased end-diastolic length with a parallel contour to the control curves. The lengthening was not symmetrical for all wall segments since $F 25$ showed a loss of amplitude (Fig. 6) most noted where the control and post-propranolol plots cross.

\section{Pressure-volume measurements}

Before describing the results of frame-by-frame diastolic pressure volume measurements in these

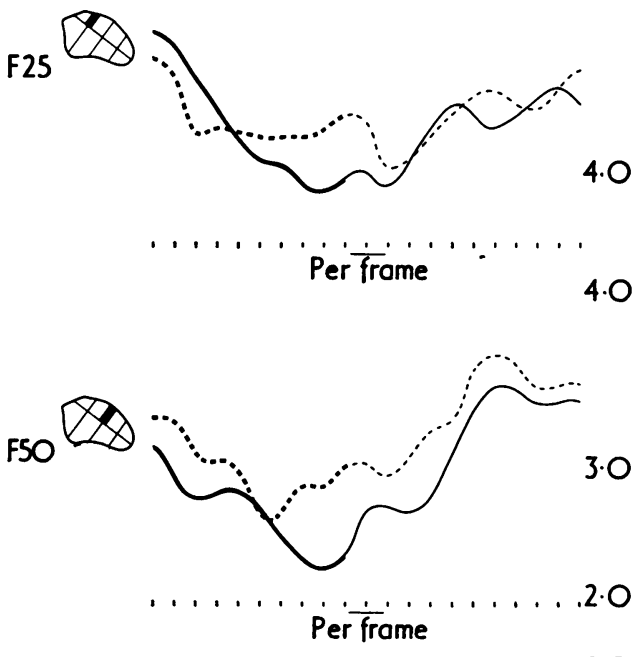

$2 \cdot 5$

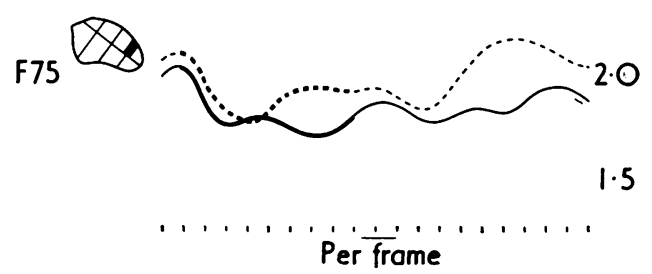

FIG. 6 A frame-by-frame plot of the $F_{25}, F_{50}$, and $F 75$ radii in a group $B$ patient before (continuous line) and after (stippled line) propranolol. Radii length is shown on the vertical axis. The darkened part of the continuous and stippled line represents systolic shortening. patients, several comments concerning their method of determination are appropriate. Fig. 9 shows a graph of both the pressure and volume data points obtained in two duplicate studies performed 30 minutes apart in a patient with a normal coronary arteriogram and normal left ventriculogram. Enddiastolic volume is seen at approximately the peak of the $\mathbf{R}$ wave, decreases rapidly during systole to the end-systolic volume, and increases rapidly to a brief plateau followed by atrial systole. It can be seen that a substantial amount of diastolic ventricular filling takes place before minimum diastolic pressure is reached. This limits the determination of diastolic pressure-volume relation to the period from the nadir of the diastolic pressure to the peak of the ' $a$ ' wave. It has also been our observation that volume measurements can be highly reproducible from study to study provided that time is allowed to elapse for the effects of contrast to dissipate. Small shifts in left ventricular filling pressures between the initial and duplicate studies have been observed and may result from variations of respiratory effort during the pressure measurements.

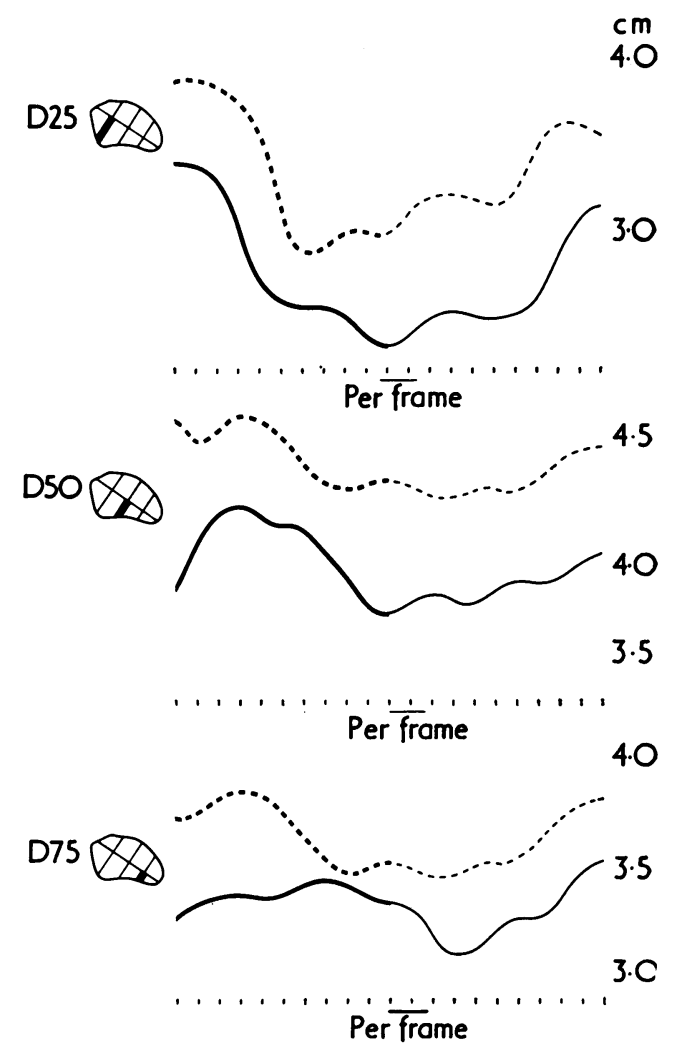

FIG. 7 A frame-by-frame plot of the D25, D50, and $D_{75}$ radii, conventions as in Fig. 6. 


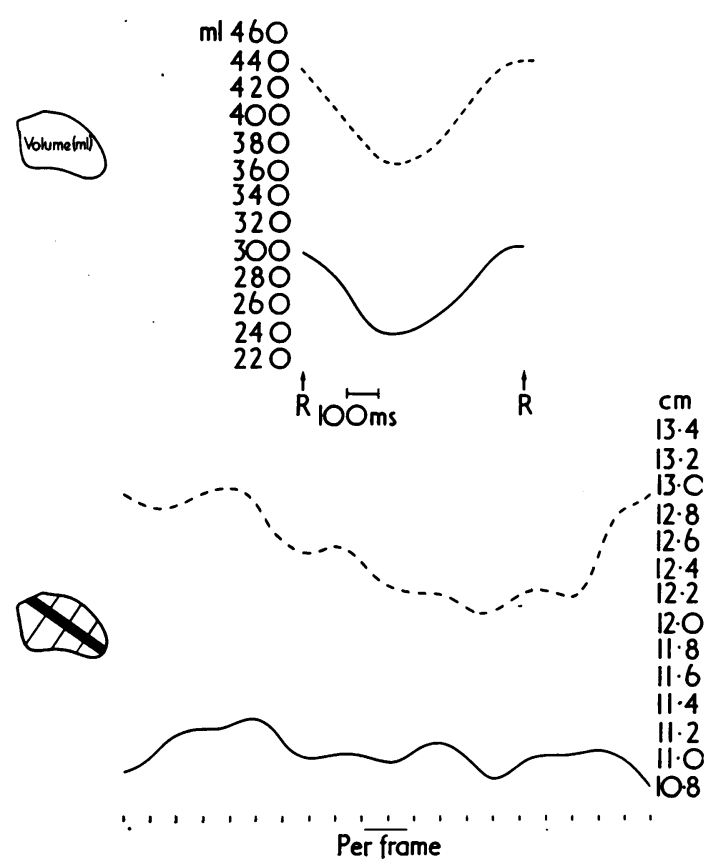

FIG. 8 A frame-by-frame plot in a group $B$ patient of left ventricular volume and chord length. $A$ similar notation as in Fig. 6 is used. The $R$ wave of the $Q R S$ complex is indicated below the volume plot.

Fig. Io shows the frame-by-frame pressure volume data from one of the group $B$ patients (patient $3 \mathrm{~B}$ ) who had shown depressed cardiac performance after propranolol. In this individual all diastolic volumes were increased by approximately $30 \mathrm{ml}$. In Fig. II are shown the same data plotted with the natural logarithm of the pressure on the $Y$ axis and the ventricular volume on the $X$ axis. There has been a shift of the pressure volume relation to the right after propranolol administration. The slopes of the regression lines fitted to these data are similar (Table 2).

Fig. I2 illustrates an average of the regression lines for each group of patients calculated from the frame-by-frame log pressure and volume data for each patient. A best fit regression line was obtained for each of the individual data curves, and then the two end points were averaged in order to construct a composite curve. The regression lines of group A patients were minimally altered whereas the group B patients showed a substantial shift of the regression line to the right without slope change. Though the standard errors, shown by the brackets, were too large for this change to reach statistical significance, the trend exhibited here was consistent for all group B patients.

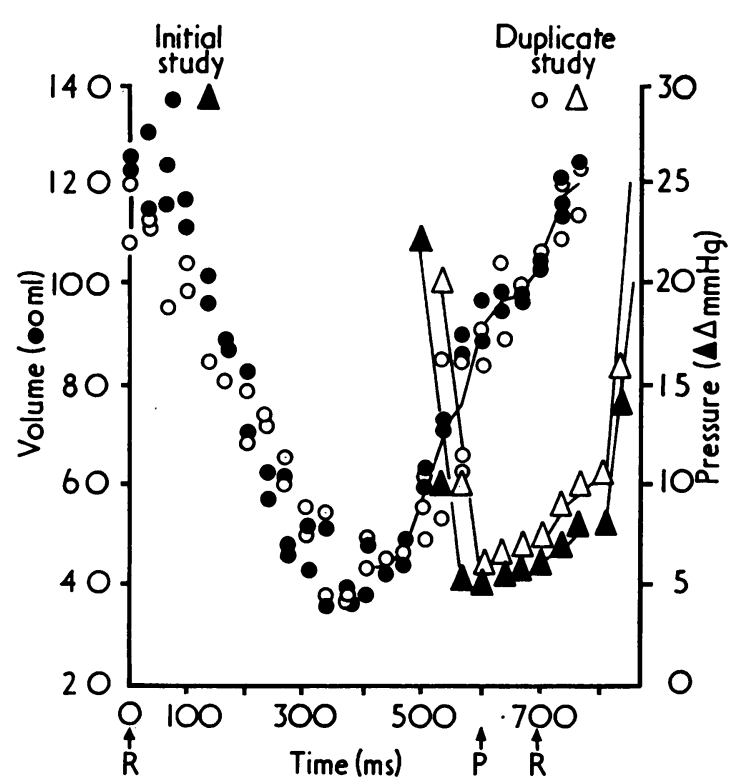

FIG. 9 Graph of simultaneous pressure and volume data in duplicate studies performed 30 minutes apart in a group $A$ patient. Volume data are shown in circles, the pressure with triangles. Initial study indicated with the closed symbols, the duplicate study with the open symbols. The horizontal axis is the time scale and the pacing spike $(P)$ and $R$ wave of the $Q R S$ complex are indicated. There is a $40 \mathrm{~ms}$ delay in the pressure signal inscription imposed by the electronic filter.

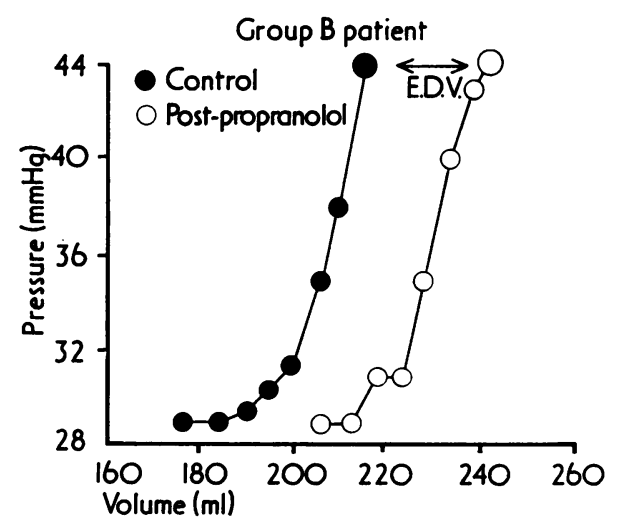

FIG. IO Graph of frame-by-frame pressure volume data from a group $B$ patient $(3 B)$. Control observations are shown in the closed circles, after propranolol with the open circles. 


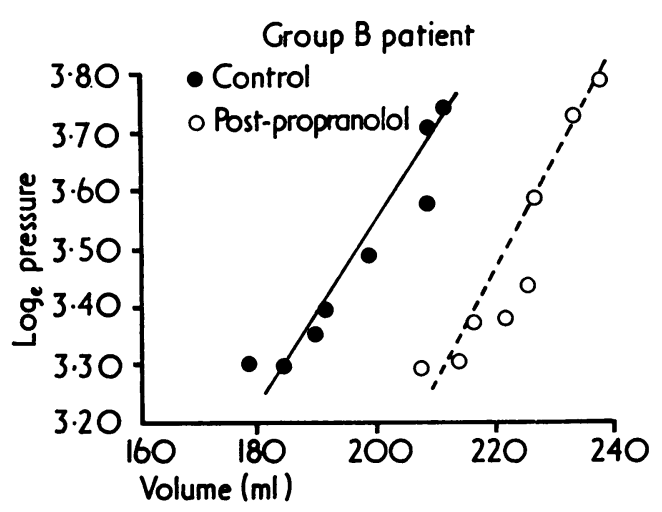

FIG. II Graph showing the log pressure-volume plot from the group $B$ patient $\left({ }_{3} B\right)$ in Fig. 10.

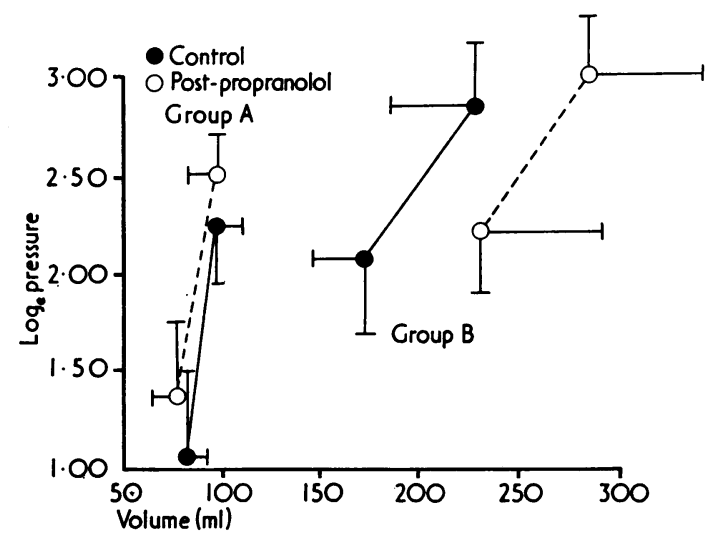

FIG. I2 Composite log pressure-volume curves for group $A$ and $B$ patients (see text).

Table 2 shows the data for the haemodynamic effects of propranolol in each individual patient.

\section{Discussion}

\section{Critique of technical considerations}

Studies of pressure-volume relation in the intact human ventricle require accurate ventricular volume determination with simultaneous high fidelity pressure recordings. The volume of dye given in the angiocardiograms in this study enabled accurate determination of left ventricular volume to be performed. It was shown that the angiographic dye had no effect on left ventricular performance 25 minutes later as there was essentially no change from the control haemodynamic state or in end-systolic and end-diastolic volumes in group A patients. Other workers have shown that sequential left ventricular end-diastolic and end-systolic volumes measured over 3 to 5 cardiac cycles after contrast administration demonstrate no change from the control state (Hammermeister and Warbasse, 1973). Biplane angiocardiography would have been of considerable aid in delineating more accurately the assessment of ventricular volume and also of any asymmetrical septal wall motion pattern. However, septal asynergy which might cause single plane angiocardiograms to be erroneous was eliminated in this study both by echocardiography and by ensuring a close correlation between different techniques in stroke volume determination.

The catheter-tip pressure transducer used in this study is an ultraminiature pressure transducer designed with features of thermostability, longterm stability, high output level with excellent linearity, and negligible hysteresis at a high natural frequency. This allowed more accurate pressure measurements to be obtained, lacking the resonance often seen in fluid-filled systems. Care was taken to ensure the angiograms were taken at a similar phase of respiration (held respiration) on all occasions.

\section{Effect of propranolol on left ventricular func- tion}

Propranolol has little effect on the normal ventricle and the ventricles of patients with coronary artery disease with normal end-diastolic volumes when heart rate is controlled. Ventricular volume normally increases as heart rate decreases. This suggests the predominant action of propranolol as an anti-anginal agent is purely as a negative chronotropic agent. The log pressure-volume characteristic of these patients showed no change from control values. However, in those patients with enddiastolic volumes greater than $200 \mathrm{ml}$ there was a uniform shift to the right of the log pressurevolume (Fig. 12).

Ludbrook et al. (1973) found that doses of propranolol, sufficient to decrease systolic time interval indices of myocardial contractility, decrease heart rate, and increase heart size, did not exaggerate preexisting paradoxical wall motion or accentuate latent areas of paradox. Our studies do not confirm these findings as propranolol caused alterations in systolic segment wall motion in group B patients. It is, therefore, essential to realize that apparent hypokinesia may well be caused simply by a larger ventricle in patients treated with propranolol.

\section{Pressure-volume relation}

Pressure-volume curves are technically difficult to obtain in the clinical situation. Manometer-tipped angiocatheters have enabled accurate simultaneous pressure and volume measurements to be obtained. 
Multiple pressure-volume measurements in diastole allow the diastolic pressure-volume relation to be defined. Diamond et al. (197I) showed that the slope of this linear function provided a constant which was affected by changes in ventricular wall stiffness. Mirsky and Parmley (1973) have recently introduced an alternative approach to quantifying left ventricular wall stiffness by utilizing stressstrain relation. With such terms, comparison between elastic structures of different sizes and shapes becomes more meaningful. However, as wall mass was unaltered in this acute, within-patient intervention study, log pressure-volume relation reflects the stress-strain characteristics of the ventricle.

Two possible mechanisms are proposed to explain the observed shift in the pressure-volume curve by propranolol. Firstly, hypothesizing a reversal of active tension development produced in ischaemic areas of muscle and, secondly, a change in pressure-volume relation consequent to alteration in inotropic state in the intact ventricle. A wide variety of positive and negative inotropic agents have been studied for their effect on active compliance of isolated cardiac muscle. These studies show that acute pharmacologically induced changes in inotropic state do not influence active compliance in isolated muscle (Sonnenblick, 1964; Parmley and Sonnenblick, 1967). However, in the intact ventricle left ventricular compliance can be changed in chronic disease states, acute myocardial infarction, and chronic ventricular hypertrophy and failure (Covell and Ross, 1973).

Barry et al. (1974) have shown that during pacinginduced angina the log pressure-volume curve shifted to the left with little alteration in slope, suggesting active tension development in ischaemic muscle during angina. In this study, we found propranolol shifted this relation to the right in patients with decreased myocardial function; thus, there may be a reversal of active diastolic tension which is generated in ischaemic areas in the decompensated ventricle. The patients with minimal or no coronary disease showed no shift of log pressure-volume curves, supporting this concept. Those patients showing a shift to the right of their log pressure-volume curve were the same patients who showed impairment of myocardial function as a result of beta-adrenergic blockade. Ordinarily loss of systolic myocardial function results in an upward shift on the same log pressure-volume curve. Possibly, as diastolic pressure increases there is either a slippage or reorientation of myocardial fibres such as to shift the log pressure-volume curve to the right. This would decrease wall stress required to maintain the myocardial systolic function or contractility at the same level, and thus the patient's position on this new curve would be lower. Teleologically this would lower ventricular filling pressure and might occur with sufficient rapidity to allow the changes to occur in an acute intervention study.

These observations of the haemodynamic effects of propranolol imply that myocardial pump function of the heart cannot be accurately studied unless muscle function is also assessed.

\section{References}

Alderman, E. L., Sandler, H., Brooker, J. Z., Sanders, W. J., Simpson, C., and Harrison, D. C. (1973). Light-pen computer processing of video image for the determination of left ventricular volume. Circulation, 47, 309.

Barry, W. H., Brooker, J. Z., Alderman, E. L., and Harrison, D. C. (1974). Changes in diastolic stiffness and tone of the left ventricle during angina pectoris. Circulation, 49, 255.

Covell, J. W., and Ross, J. (1973). Nature and significance of alterations in myocardial compliance. American fournal of Cardiology, 32, 449.

Diamond, G., Forrester, J. S., Hargis, J., Parmley, W. W., Danzig, R., and Swan, H. J. C. (197I). Diastolic pressurevolume relationship in the canine left ventricle. Circulation Research, 29, 267.

Gaasch, W. H., Battle, W. E., Oboler, A. A., Banas, J. S., and Levine, H. J. (1972). Left ventricular stress and compliance in man. Circulation, 45, 746.

Hammermeister, K. E., and Warbasse, J. R. (1973). Immediate hemodynamic effects of cardiac angiography in man. American fournal of Cardiology, 31, 307.

Ludbrook, P., Karliner, J. S., Kostuk, W., and O'Rourke, R. A. (1973). Effects of intravenously administered propranolol on wall motion abnormalities. American fournal of Cardiology, 31, 712.

Mirsky, I., and Parmley, W. W. (1973). Assessment of passive elastic stiffness for isolated heart muscle and the intact heart. Circulation Research, 33, 233.

Parmley, W. W., and Sonnenblick, E. H. (1967). Series elasticity in heart muscle. Its relation to contractile element velocity and proposed muscle models. Circulation Research, 20, II2.

Sonnenblick, E. H. (1964). Series elastic and contractile elements in heart muscle: changes in muscle length. American fournal of Physiology, 207, I330.

Requests for reprints to Dr. John Coltart, St. Thomas' Hospital, London SEr $7 \mathrm{EH}$. 